\title{
НОВЫЙ ГЛОБАЛЬНЫЙ ПОДХОД ЕС К МИГРАЦИИ И МОБИЛЬНОСТИ (GАММ) И СОЦИАЛЬНЫЕ АСПЕКТЫ МИГРАЦИОННОЙ ПОЛИТИКИ ИТАЛИИ
}

\begin{abstract}
Аннотация: в эпоху колоссальных миграционных потоков несомненными преимуществами итальянского подхода к миграциионой проблематике является всеобщая единая линия, основанная на историческом опыте Италии и общеевропейской глобальной политике в сфере миграции, ориентированной не только на использование дешевого труда мигрантов, но и на понимание ответственности перед ними. Данная статья освещает социальный вектор развития миграционной политики Италии, который направлен на усиление контроля над въездом и пребыванием иностранцев в стране и на их социальную адаптацию и интеграцию. Опыт Италии в данной области, изучение механизмов осуществления миграчионной политики представляется целесообразным при проведении реформы миграционного законодательства в Российской Федерации. Заслуживающими особого внимания аспектами являются существенные достижения в борьбе с нелегальными мигрантами путем повышения социальной ответственности самих иммигрантов, что может быть достигнуто благодаря проводимой политике вовлечения иммигрантов в систему формирования пенсионных фондов, сочиальных взносов, когда иммигранты заинтересованы в том, чтобы продемонстрировать свой вклад и т.n.
\end{abstract}

Ключевые слова: миграционная политика, законодательство Италии, социальная ответственность, интеграция мигрантов, нелегальные иммигранты, медицинское обслуживание иммигрантов, пенсионные выплаты, координация, интеграция.

Review: At the time of great migration flow, the Italian approach to migration problems has obvious advantages due to the united position, which is based upon the Italian historical experience and European global policy, and which is aimed not only at the use of cheap labor of migrants, but also at understanding of responsibilities towards them. This article includes analysis of the social vector of development in the migration policy of Italy, which is aimed to strengthen the control over the foreigners entering and residing in Italy, their social adaptation and integration. The Italian experience in this sphere and its migration policy mechanisms are worth studying within the framework of the reform of migration legislation in the Russian Federation. Special attention should be paid to the considerable achievements in fighting illegal migration by raising the social responsibility of the migrants themselves, which may be achieved thanks to the policy of involvement of immigrants into the pension funds and social funds system, so that the immigrants are interested in showing their input, etc.

Keywords: political science, migration policy, legislation of Italy, social responsibility, integration of migrants, illegal migrants, medical aid for migrants, pension payments, coordination, integration. 
B последние годы рост ксенофобии и формирование в общественном мнении непосредственной связи между проблемами безопасности и пребыванием на территории государств, массово принимающих мигрантов, заставляют политические элиты пересматривать стратегию миграционной политики, признавая необходимость привлечения рабочей силы из третьих стран, но, акцентируя заинтересованность в том, чтобы иммигранты соблюдали законы принимающей стороны и социально-культурные нормы. Речь идет о стимулировании плановой, организованной, прогнозируемой миграции как позитивной силы развития общества при наличии механизмов контроля миграционных процессов и пресечения нелегальной миграции. Общеевропейские и национальные стратегии миграционной политики cocpeдоточены на соблюдении принципиальных интересов, как принимающих стран, так и иммигрантов. Государства стремятся сохранить национальную безопасность, национальную идентичность, социально-экономическую стабильность и общественную безопасность. Иммигранты вправе рассчитывать на соблюдение основных принципов и норм международного права, направленных на обеспечение признания человеческого достоинства и связанных с ним прав и свобод, исключающих любые формы дискриминации.

Миграционная политика в Европейском Союзе заключается в выработке единого подхода к миграции у всех государств-членов ЕС. Составными частями ее являются:

- усиление борьбы с нелегальной миграцией, для чего предпринимаются меры по совершенствованию пограничного контроля на внешней границе между Европейским союзом и остальным миром;

- $\quad$ приведение в соответствие национальных законов, направленных на борьбу с нелегальной миграцией, улучшению работы со- трудников соответствующих министерств и ведомств;

- осуществление мероприятий по налаживанию региональной кооперации странучастниц Евросоюза в противодействии нелегальной миграции: группа соседствующих государств объединяет усилия для предотвращения нелегальной миграции из определенного географического региона;

- содействие развитию сотрудничества полиции стран-членов в рамках Европола при борьбе с нелегальным перемещением людей и унификация уголовных законов, наказывающих этот вид преступного бизнеса в Европе;

- осуществление мер по проведению легальной миграции;

- обеспечение информационной поддержки в третьих странах возможности легальной миграции в Европейский Союз;

- содействие привлечению высококвалифицированной и образованной рабочей силы, с правом каждого государства-члена Европейского Союза самостоятельно определять количественный и качественный состав приглашаемых мигрантов, т.е. вводить квоты.

Кроме того, иммиграция рассматривается как важный элемент отношений Европы со странами происхождения иммигрантов. Одним из основных приоритетов Европейского союза в области иммиграционной политики декларируется содействие развитию стран происхождения, чтобы содействовать улучшению положения их населения.

Европа нуждается в иммигрантах, как с демографической, так и с экономической точки зрения». Однако речь идет о приоритете «качественной» иммиграции над «количественной»,

1 Вильданов Р. Х. «Социальное обеспечение в Европейском Сообществе», Москва, ИНИОН AH,2008 г. 
т. е. о привлечении в Европу в первую очередь высококвалифицированных специалистов.

Приоритетом общеевропейской политики иммиграции становится обеспечение достойных условий существования легальных иммигрантов. Каждая страна обязана обеспечить проживание, социальное обеспечение и возможность получения образования детьми иммигрантов. Предполагается, что все эти условия будут соблюдаться во всех странах ЕС, однако количество и квалификация рабочей силы определяется каждой страной в отдельности. Согласно данной политике, «иммиграционные потоки обязательно должны быть адаптированы к возможностям европейской принимающей стороны», исходя из потребностей экономики, конкретных условий рынка национальной рабочей силы и возможностей организации приема иммигрантов.

На Саммите ЕС в Брюсселе 16.10.2008 года французский министр по делам иммиграции, Брис Ортефё заявил, что «Европа не имеет возможностей принять на достойном уровне всех тех, кто надеется на (европейское) Эльдорадо». Он отметил, что адекватно оценить работу Франции на посту председателя ЕС поможет не столько принятие совместных текстов и деклараций, сколько результаты усилий по строительству новой политики ЕС в отношении стран - источников иммиграционных потоков в духе партнерства с использованием новых механизмов регулирования и привлечения рабочей силы.

Результатом французской инициативы явилось принятие Директивы 2008/115/EC Европейского Парламента и Совета от 16 декабря 2008 года «Об общих стандартах и процедурах, подлежащих применению в государствах-членах к возврату незаконно пребывающих граждан третьих стран».

Данная Директива является законодательным актом ЕС, принятым в контексте иммиграционной политики ЕС, которая осуществля- ется на основании статьи 63 Договора об учреждении Европейского сообщества и включает в себя, с одной стороны, меры по регулированию законного пребывания на долгосрочной основе (свыше трех месяцев в полугодие) граждан третьих стран в ЕС, с другой стороны, меры по борьбе с нелегальной иммиграцией. В качестве гармонизации национальных правовых систем данная Директива закрепляет комплекс единообразных принципов и норм, которые каждое из государств-членов ЕС, а равно ассоциированные участники «Шенгенских соглашений» - Исландия, Норвегия, Швейцария и Лихтенштейн - трансформировали в свое внутреннее законодательство, за исключением Дании, Великобритании и Ирландии.

18 ноября 2011 года вступила в силу новая политика ЕС относительно миграции и мобильности, целью которой является более эффективное использование потенциальных взаимовыгодных преимуществ миграции. Новый Глобальный подход к миграции и мобильности (Global Approach to Migration and Mobility - GAMM), предложенный Еврокомиссией, призван развить диалог и укрепить партнерство со странами, не входящими в состав ЕС, а также способствовать благоденствию Европы с учетом динамичных демографических и экономических изменений, с которыми приходится считаться европейскому сообществу. В рамках этого подхода больше внимания уделяется мигрантам, их поддержке и защите их прав в их родных странах, а также транзитных государствах и странах назначения. Документ гласит: «Мобильность граждан третьих стран через внешние границы ЕС важна, поскольку этот вопрос затрагивает интересы широких кругов людей, таких как краткосрочные посетители, туристы, студенты, исследователи, бизнесмены или лица, навещающие родственников. Для обеспечения своего благоденствия в условиях международной конкуренции за талан- 
тливых граждан Европа должна стать более привлекательным местом назначения».

Еврокомиссар по внутренним делам, Сесилия Мальмстрем, заявила: «Мы создаем стратегические и политические рамки для миграции и разработки, которые будут понятными и единообразными. ЕС сможет более эффективно управлять миграцией в своих границах и за их пределами только при условии более активного диалога и сотрудничества со странами-партнерами. Новый Глобальный подход ЕС к миграции и мобильности представляет собой стратегические рамочные условия, необходимые для более успешных действий ЕС в целом и отдельных стран-членов в этой области».

Приоритет в данной инициативе отдан двум основным рамочным направлениям:

- партнерство в вопросах мобильности, в первую очередь, будет предложено странам, непосредственно граничащим c EC, а также Тунису, Марокко и Египту. Это предусматривает конкретный набор рамочных условий для развития диалога и сотрудничества, нацеленных на упрощение и организацию легальной миграции, принятие эффективных и гуманных мер по решению проблемы нелегальной миграции, а также на выполнение конкретных действий для более интенсивного использования предоставляемых миграцией возможностей развития. Следовательно, неотъемлемой частью такого партнерства станут упрощение визовых процедур и соглашения о возврате нелегальных мигрантов;

- $\quad$ другим странам Еврокомиссия предлагает принять участие в совместных планах действий по вопросам миграции и мобильности, которые предусматривают углубленное сотрудничество, основанное

${ }^{1}$ См.- - сайт Евросоюза,- - www.enpi-info.eu, обращение 27.07.2012 на многочисленных совместно разработанных рекомендациях, поставленных целях и обоюдном стремлении к диалогу и сотрудничеству. Для предоставления ресурсов и поддержки отдельным гражданам и странам-партнерам в области определения востребованных специальностей и целенаправленного трудоустройства будут учреждены ресурсные центры по вопросам миграции и мобильности. С этой целью был открыт специальный вэб-портал ЕС по вопросам иммиграции, который станет дополнительным источником информации для мигрантов и поможет сделать сознательный выбор при рассмотрении возможностей выезда в ЕС.

Новая инициатива стремится к более тесной интеграции с внешней политикой ЕС и сотрудничеству в области развития ЕC, в частности, со Стратегией «Европа-2020» и с государственными деятелями в сферах трудоустройства и образования.

Как член ЕС Италия, несмотря на серьезный экономический кризис и увеличение потока иммигрантов, осуществляет национальную миграционную политику в соответствии с нормами международного и европейского права. Необходимо отметить, что, согласно вступившей в силу 1 января 1948 года Конституции Итальянской республики, Италия является демократической Республикой, основанной на труде (ст. 1) и признает и гарантирует неотъемлемые права личности (ст. 2), требуя выполнения неотъемлемых обязанностей, вытекающих из политической, экономической и социальной солидарности. В связи с этим, такие фундаментальные права человека, как охрана здоровья (ст. 32), создание семьи (ст. 29), бесплатное среднее образование (ст. 34), обеспечивающий достойное существование труд (ст. 36), право собственности (ст. 42) закреплены Конституцией и в отношении лиц, не являющихся гражданами. Одновременно, 


\section{Тренды и управление - №3(3)•2013}

на лиц, не являющихся гражданами, статьей 53 возлагается обязанность участвовать в государственных расходах в соответствии со своими возможностями.

Основной закон Италии предопределил эволюцию национального миграционного законодательства при главенствовании принципа равенства трудящихся, способствующего эффективному их участию в политической, экономической и социальной организации страны.

По данным последней всеобщей переписи, данные которой были опубликованы 27 апреля 2012 г., население Италии составляет 59464644 чел. ${ }^{1}$ Из них 93,52\% итальянцы, 90\% - католики, 99\% - грамотные. Уже несколько лет ежегодный прирост населения- около 1 млн. чел. Интересно, что общее число считающих себя итальянцами, постоянно проживающих за пределами Италии, по разным источникам составляет 55-60 млн.чел.

Структура занятости населения: сельское хозяйство - 4\%, промышленность - 31\%, мелкий бизнес, сфера услуг и туризм - 65\%.

В 2010 году в Италии было зарегистрировано 4235054 иммигранта, но в связи с событиями в Северной Африке, их число в 2011, включая нелегальных иммигрантов, превысило 5 млн.человек, что составило $12 \%$ от всего населения. Количество иностранцев, имеющих регистрацию составило 4,9 млн.человек, а постоянно выплачивающих налоги - 3,77 млн.человек. ${ }^{2}$

Трудовые иммигранты приносят экономике Италии больше, чем получают от нее. По данным Национального Фонда Пенсионного Обеспечения - НФПО (INPS) за год общие отчисления иммигрантов составляют около 7,5

\footnotetext{
${ }^{1}$ «Primirisultati del 15 Censimentodellapopolazione e
delleabitazioni», 27.04.2012 - www.Istat.it, обращение

${ }^{1}$ «Primirisultati del 15 Censimentodellapopolazione e
delleabitazioni», 27.04.2012 - www.Istat.it, обращение 27.07.2012 2 Данные переписи населения от 27.04.2012,_- www.Istat. it, обращение 27.07.2012
} 66 Все права принадлежат издательству () NOTA BENE (OOO «НБ-Медиа») www.nbpublish.com гистрировано 21108368 работающих, из них 2727254 чел.- иммигранты, что составляет $12,9 \%$ от числа выплачивающих пенсионные и социальные взносы. При этом только 110 тысяч иностранцев получают пенсии в Италии. Учитывая, что средний возраст иммигрантов составляет 31 год, а итальянцев - 43,5 лет, можно утверждать, что трудовые легальные мигранты положительно влияют на социально-экономическую ситуацию в Италии в настоящее время.

В Италии 3,77 млн. иностранцев платят налог на доходы физических лиц (Irpef). Иммигранты составляют 6,8\% налогоплательщиков. В среднем сумма налога достигает 2810 евро с человека, по сравнению с 4865, которую платят налогоплательщики, родившиеся в Италии. В масштабах страны налогоплательщики, рожденные заграницей, платят около 7 млрд. евро, а общий процент налоговых взносов составляет 4,1\%.

65\% иммигрантов подают налоговые декларации в полном соответствии с законом. Это объясняется тем, что иммигранты получают больше налоговых льгот, по сравнению с итальянцами, в основном из-за низких доходов, а также тем, что иммигранты заинтересованы демонстрировать законопослушность для дальнейшего продления вида на жительство.

Итальянские работодатели обязаны выплачивать специальный налог (contributo) на каждого привлеченного работника-иммигранта за прошедший год. Так, за 2011 год установленный срок выплаты налога на привлечение трудовых иммигрантов был установлен до 10 апреля 2012 года. При этом итальянская социальная и налоговая системы предусматривают льготы для законопослушных работодателей до 1549 евро в год, нанявшим домашних помощников, и до 2100 евро, нанявшим сиделок. Компенсация выплачивается НФПО при предъявлении квитанций, но только тем, 
чей годовой доход не превышает 40000 евро. Подать документы на получение компенсации может не только работодатель, но и инвалид, за которым осуществляется уход.

В тоже время и трудящиеся мигранты имеют возможность выплачивать добровольные взносы в пенсионный фонд (versamenti volontari) даже в случае неполной занятости. Такое право предоставляется работникам, заключившим трудовой договор после 31.12.1996 ${ }^{1}$. Для получения разрешения на продолжение добровольной уплаты взносов застрахованное лицо должно соответствовать одному из следующих требований:

1) иметь не менее 5-ти лет уплаченных взносов (260 еженедельных взносов, или 60 ежемесячных взносов), независимо от сроков уплаты взносов;

2) иметь не менее 3-х лет уплаченных взносов в течение 5-ти лет, предшествующих дате подачи запроса. Добровольные взносы можно совмещать с единовременным взносом, уплачиваемым в обязательном порядке НФПО по месту жительства по форме № 10/м/02/РТ или в Патронат (общественная организация помощи трудящимся при органе местного самоуправления), где предоставляются услуги на безвозмездной основе. К запросу нет необходимости прилагать никакую дополнительную документацию, т.к. вся информация содержится в информационных базах НФПО. ${ }^{2}$

Разрешение на добровольную уплату взносов может быть выдано работнику для покрытия:

- полного периода или в дополнение к периодам, в течение которых он работал неполный рабочий день; оплата должна быть произведена в виде единовременной выплаты в предусмотренные сроки (до конца

\footnotetext{
1 Распоряжение Минсоцразвития Италии № 220 от 14.11.1996 г.

${ }^{2}$ Циркуляр Минсоцразвития Италии № 29 от 23.02.2006 г.
}

квартала, следующего за тем, в котором было получено разрешение);

- периодов, следующих после подачи запроса в связи с прекращением трудовой деятельности; уплата взносов должна осуществляться в порядке, предусмотренном для большинства работников (единовременным платежом, ежеквартально в последний день календарного квартала, следующего за тем, к которому относятся взносы).

- НФПО, рассмотрев запрос, направляет непосредственно работнику уведомление о принятии запроса с приложением бланка, который должен быть использован для уплаты взноса на расчетный счет через государственную корпорацию «Почта Италии». Запрос направляется заказным письмом, с уведомлением о вручении. Оплата должна быть произведена не позднее истечения квартала, следующего за тем, в котором было получено уведомление. Добровольные взносы позволяют покрыть:

- общий срок для того, чтобы определить как право, так и размер пенсии, если они уплачены работником, осуществляющим трудовую деятельность «part-time» по вертикальной системе, другими словами, в течение чередуемых дней, недель или месяцев, в течение которых он не работал полный рабочий день;

- $\quad$ в дополнение, только лишь в целях определения размера пенсии, если они были уплачены работником, осуществляющим трудовую деятельность «part-time» по горизонтальной системе, т. е. в течение недель, полностью покрытых взносами, когда трудовая деятельность осуществлялась в течение неполного рабочего дня (циркуляр MCP № 29 от 23.02.2006). Добровольные взносы, уплачиваемые в дополнение к обязательным взносам, учитываются при пре- 


\section{Тренды и управление - №3(3) • 2013}

доставлении права на пенсию, если общая сумма взносов после уплаты добровольных взносов, превысит минимальную сумму, необходимую для предоставления права на пенсию, предусмотренную ст. 7 Закона № 638 от 11 ноября 1983 (циркуляр № 29 от 23.02.2006).

Итальянское общество лояльнее относится к нелегальным иммигрантам, чем граждане соседних стран. Выполняя обязательства, взятые на себя в качестве члена ЕС, итальянские власти интерпретируют нормы общеевропейского права, касающиеся отношения к нелегальным иммигрантам, менее императивно,

Незаконное нахождение в стране иммигранта (clandestino) не может само по себе являться препятствием для заключения им брака с гражданином (гражданкой) Италии. Такое решение было принято Конституционным судом, признавшим частично незаконным п.1. ст. 116 ГК, в котором говорится: «Иностранный гражданин, желающий вступить в брак в стране, должен представить в орган гражданского состояния заявление, выданное компетентным органом своей страны, о том, что в соответствии с законодательством, ему разрешается заключить брак». Текст был взят из «пакета безопасности» 1994 года с поправками, внесенными в 2009 году. Согласно постановлению суда, брак между гражданином Италии и иностранным гражданином возможен даже в случае, когда иностранец нелегально находится на территории страны.

Суд повторил решение Европейского суда, удовлетворив иск итало-марокканской пары из Катании, которая оспаривала отказ в регистрации брака. Суд также указал: «Остается в силе то, что незыблемые права, в соответствии со статьей 2 Конституции, принадлежат личности не в связи с ее принадлежностью определенному политическому сообществу, а как права человека. Поэтому правовой статус иностранцев не следует рассматривать в части, касающейся защиты этих прав, как повод для худшего к ним отношения».

Кроме того, Конституционный суд постановил, что ограничение права иностранца, помимо того, что подразумевает безусловное ограничение соответствующего права итальянского гражданина, желающего вступить с ним в брак, в том числе, не является адекватным средством противодействия так называемым «бракам по расчету», учитывая, что для этого существуют отдельные институты.

Необходимо подчеркнуть, что нелегальные иммигранты имеют право не только оформлять браки, но и записывать своих детей в учебные заведения. Кроме того, они имеют право на получение амбулаторного лечения, скорую помощь в условиях госпитализации и любые другие жизненно важные типы медицинской помощи, в том числе и длительного характера, сопряженные с болезнями или несчастными случаями, наравне с гражданами и легальными иммигрантами.

Такую помощь им оказывают в государственных или аккредитованных частных медицинских учреждениях. Для этого нелегальный иммигрант может обратиться в Государственную Санитарную Службу (ASL) за получением 6-месячной медицинской карточки временно проживающего иностранца (Straniero Temporaneamente Presente), предоставив данные паспорта и письменную декларацию об отсутствии материальных средств. Можно попросить не указывать в карточке фамилии или имени,- - она будет считаться действительной. Медицинские структуры обязаны оказать помощь, но не обязаны автоматически передавать информацию о нелегальном иммигранте в органы управления о лечении в случае, если нет угрозы для общества. Такая информация передается только при поступлении запроса из Квестуры. 
Многие годы в Италии существовала система амнистии для нелегальных иммигрантов - санатории (Sanatoria amministrativa). Санаторий предусматривал легализацию нелегальных работников, уже находящихся и работающих без официальных контрактов на территории Италии. Последний санаторий был объявлен Правительством Республики в 2009 году.

Но легализоваться смогли лишь те работники, которые получили согласие своего работодателя. Очевидно, что работодатель, принявший на работу нелегалов, преследует определенные цели: сокращение издержек производства, уход от налогов, неисполнение социальных обязательств. Поэтому воспользоваться последним санаторием смогли немногие. После введения санкций по отношению к предпринимателям, использующим нелегальную рабочую силу, представляется, что объявление санаториев по прежнему принципу становится бессмысленным.

В завершении следует отметить, что отличительной чертой миграционной политики Италии является ее гуманный характер, обусловленный основным национальным законом и историческим опытом нации, которая в течение последних ста лет прошла три различных этапа миграции:

1) являясь поставщиком легальных и нелегальных мигрантов в более развитые страны в конце XIX - начале XX веков;

2) пережив колоссальную внутреннюю миграцию середины XX века;

3) принимая потоки иммигрантов в конце XX - начале XXI веков.

Исторический обзор подтверждает также, что итальянское общество придерживается принципа, сформулированного древнеримским философом и консулом Марком Туллием Цицероном: «Главное искусство жизни состоит в том, чтобы решать проблемы по мере их возникновения, а не падать духом, заранее пугая себя тем, что когда-то они появятся». Этот принцип неоднократно использовался и в течение последнего десятилетия для решения кризисных ситуаций в области миграционной политики, когда экстренно принимались законодательные нормы, порой не соответствующие общеевропейскому законодательству, но способствующие разрешению кризиса и установлению общественного порядка. Впоследствии данные нормы отменялись.

При сопоставлении глобальной европейской стратегии миграционной политики и итальянского подхода становится очевидным, что при реализации миграционной политики в контексте общеевропейской стратегии, Италия имеет особенности:

1. приоритетными являются общеевропейские направления:

а) контроль над количественным и качественным составом иммигрантов,

б) реализация проектов по их интеграции в общество,

в) реализация основных прав человека для всех иммигрантов, включая нелегальных; 2. несомненными преимуществами итальянского подхода к данной тематике являются:

a) принцип ответственности перед иммигрантами главенствует над стремлением использовать дешевую рабочую силу для развития экономики;

б) вектор развития миграционной политики направлен не только на усиление контроля над въездом и пребыванием иностранцев в стране, но и на их скорейшую социальную адаптацию;

в) воспитание толерантности;

г) организация системы обеспечения также нелегальных иммигрантов медицинским обслуживанием и возможностью обучения.

Изучение опыта Италии в данной области, механизмов его осуществления представляется целесообразным при проведении реформы миграционного законодательства 
в Российской Федерации. Заслуживающими особого внимания аспектами являются существенные достижения в борьбе с нелегальными мигрантами путем повышения социальной ответственности самих иммигрантов. Данный результат был достигнут благодаря проводимой политике вовлечения иммигрантов в систему формирования пенсионных фондов, социальных взносов, когда иммигранты заинтересованы в том, чтобы продемонстрировать свой вклад. Одновременно, государство обеспечивает иммигрантам возможность получения меди-

\section{Библиография}

1. Европейский Пакт об иммиграции и предоставления убежища, принятый 16.10.2008 г. в Брюсселе - http://www.ambafrance-ru.org

2. Директива 2008/115/ЕС Европейского Парламента и Совета от 16.12.2008 г. «Об общих стандартах и процедурах, подлежащих применению в государствахчленах к возврату незаконно пребывающих граждан третьих стран» — http://www.icqc. $\mathrm{eu} / \mathrm{ru} / \mathrm{EU}$-directive.php

3. Глобальный подход ЕС к миграции и мобильности (GAMM) от 18.11.2011 г.http://www.enpi-info.eu/maineast. php?id=27122\&id_type=1\&lang_id=471

4. Конституция Итальянской Республики 1947 г._- http://www.quirinale.it/qrnw/statico/ costituzione/pdf/costituzione.pdf

5. УК Италии 16.09.2010 — http://www. testolegge.com/italia/codice-penale

6. Распоряжение Министерства труда и социальной политики Италии № 220 от 14.11.1996 г.http://www.lavoro.gov.it/lavoro

7. Циркуляр Министерства труда и социальной политики Италии № 29 от 23.02.2006 г.— http://www.lavoro.gov.it/ lavoro цинской помощи, образования. С введением «Интеграционного соглашения» в 2012 году иммигранты получают определенные преимущества при продлении видов на жительство при приобретении или аренде недвижимости, получении дополнительного образования. Надо отметить, что в последние годы максимально снижены бюрократические процедуры, а необходимую информацию государственные и местные органы власти получают из центральной информационной базы. Подобный опыт вполне может применяться и в российских условиях.

8. Вильданов Р. Х. «Социальное обеспечение в Европейском Сообществе», «ИНИОН АН» Москва 2008 г.

9. Сайт Европейского Союза,- - www.enpiinfo.eu

10. Официальный сайт Национального Фонда Пенсионного Обеспечения Италии.www.inps.it

11. Сайт Государственного статистического агентства Италии.- www.istat.it

\section{References (transliterated)}

1. Evropeiskii Pakt ob immigratsii i predostavleniya ubezhishcha, prinyatyi 16.10.2008 g. v Bryussele — http://www. ambafrance-ru.org

2. Direktiva $2008 / 115 /$ ES Evropeiskogo Parlamenta i Soveta ot 16.12.2008 g. «Ob obshchikh standartakh i protsedurakh, podlezhashchikh primeneniyu v gosudarstvakh-chlenakh k vozvratu nezakonno prebyvayushchikh grazhdan tret'ikh stran» http://www.icqc.eu/ru/EU-directive.php

3. Global'nyi podkhod ES k migratsii i mobil'nosti (GAMM) ot 18.11.2011 g.- http://www. enpi-info.eu/maineast.php?id=27122\&id_ type $=1 \&$ lang_id=471 
4. Konstitutsiya Ital'yanskoi Respubliki 1947 g.- http://www.quirinale.it/qrnw/statico/ costituzione/pdf/costituzione.pdf

5. UK Italii 16.09.2010 — http://www.testolegge. com/italia/codice-penale

6. Rasporyazhenie Ministerstva truda i sotsial'noi politiki Italii № 220 ot 14.11.1996 g.— http:// www.lavoro.gov.it/lavoro

7. Tsirkulyar Ministerstva truda i sotsial'noi politiki Italii № 29 ot 23.02.2006 g.- http://www.lavoro.gov.it/lavoro

8. Vil'danov R. Kh. «Sotsial'noe obespechenie v Evropeiskom Soobshchestve», «INION AN» Moskva $2008 \mathrm{~g}$.

9. Sait Evropeiskogo Soyuza, - www.enpi-info.eu

10. Ofitsial'nyi sait Natsional'nogo Fonda Pensionnogo Obespecheniya Italii. - www. inps.it

11. Sait Gosudarstvennogo statisticheskogo agentstva Italii. - www.istat.it 